\title{
Reforma, orden y concierto en el Perú del siglo XVII: el arbitrio de Joan de Belveder*/
}

\author{
Reform, Order and Concert in 17th Century Peru: \\ The arbitrio of Joan de Belveder
}

\section{Margarita Suárez.}

Pontificia Universidad Católica del Perú

Este artículo analiza la vida y la obra de Joan de Belveder, matemático aragonés, que llegó al Perú hacia fines del siglo XVI para dedicarse al comercio. Publicó en Lima una obra sobre las equivalencias de oro y plata y, además, inmerso en el espíritu del arbitrismo, escribió un largo memorial acerca de la situación general del reino del Perú y de los asuntos que debían resolverse con más urgencia, que abarca temas como el manejo de la real hacienda, la evasión de impuestos, el fraude en los gastos del estado, el contrabando en el comercio atlántico y asiático, y el cultivo de productos que competían con aquellos elaborados en España. La obra de Belveder brinda un excelente panorama acerca de los principales problemas de la administración hispana y del comercio en el Perú a inicios del siglo XVII.

Palabras Clave: Arbitrismo; Administración; Malversación; Comercio; Política monetaria; Matemáticas; Equivalencias de oro y plata; Siglo XVI; Siglo XVII; Joan de Belveder; Perú.

This article analyzes the life and work of Aragonese mathematician Joan de Belveder, who arrived in Peru at the end of the 16th century to make a living as a merchant. He published in Lima a work on gold and silver equivalents and, imbued with the spirit of arbitrismo, wrote a long memoir describing the general situation of the Kingdom of Peru and drawing attention on several matters that called for urgent resolution, including royal finance, tax evasion, embezzlement, smuggling in Atlantic and Asian trade, and the cultivation of crops competing with those produced in Spain. Belveder's work provides an excellent overview of the main problems facing the Spanish administration and trade in Peru at the beginning of the 17th century.

KeYwords: Arbitrismo; Administration; Embezzlement; Trade; Monetary Policy; Mathematics; Silver and gold equivalents; 16th century; 17th century; Joan de Belveder; Peru.

* Esta investigación es parte del proyecto «Negociando el poder», código 70242.3010, que financia la Pontificia Universidad Católica del Perú (PUCP) a través de su Dirección de Gestión de la Investigación (DGI). Quiero agradecer a Dionisio de Haro y a Augusto Espinoza por el apoyo brindado en la realización de este artículo. 


\section{El virreinato del Perú y sus arbitristas}

El hallazgo de los territorios americanos, no cabe duda, transformó a la monarquía hispánica. La necesidad de establecer un imperio que atravesase dos océanos y que implicaba someter a grupos sociales heterogéneos, trasladar población peninsular, implantar funcionarios reales, articular comercios de larga distancia y, además de todo ello, sacar frutos, puede resultar inverosímil para el observador contemporáneo, dadas las condiciones de las monarquías absolutas recién formadas. Y también fue difícil de asimilar para los españoles que habitaban en los reinos hispánicos en el siglo XVI, sobre todo luego que pudieron observar el cúmulo de tropiezos que encontraron en el camino. En efecto, ya hacia fines del siglo XVI e inicios del XVII diversos pensadores centraron su atención en Castilla y en las nefastas consecuencias que le había acarreado a su economía el manejo de las posesiones americanas: alza de precios, fuga de capitales hacia otros centros financieros europeos, y abandono de los sectores productivos tradicionales. ${ }^{1}$ En la década de 1640 ya era inequívoca la existencia de una crisis de confianza que fue atribuida indistintamente a causas naturales o sobrenaturales, y que exigía a Castilla volver sobre sus pasos para restaurar y reformar los daños de la república. ${ }^{2}$

La preocupación de Castilla por los efectos económicos del manejo de las Indias no solo estaba referida a los problemas internos o a su relación con los demás reinos europeos. Ya desde el siglo XVI América, y específicamente el Perú, habían dado muestras de autosuficiencia económica y se había puesto en evidencia que el accionar político debía ser negociado. ${ }^{3} \mathrm{La}$ colonización del Perú presentó la resistencia de la población indígena, pero también la tenaz rebeldía de los encomenderos españoles, que colocaron a los funcionarios reales en serios problemas para lograr una efectiva pacificación del reino. De allí en adelante dialogar con los descendientes de los conquistadores sería una tarea tediosa que colocaría en aprietos a más de un vice-soberano. Los descendientes de los conquistadores clamaban por su derecho a participar en el gobierno y tener prioridad en el reparto de cargos y mercedes. Los virreyes, pues, debían negociar con los «beneméritos» sus privilegios por haber conquistado el reino, y también debían pactar

\footnotetext{
1 Perdices-Reeder, 2003, 239.

2 Elliott, 2007, 313.

3 Lynch, 1992 y 1993.
} 
constantemente con los otros miembros de la élite de poder en materias referentes a aumento de impuestos, envío de remesas y colaboración comercial. Mantener el equilibrio no fue tarea fácil $\mathrm{y}$, de hecho, hubo coyunturas muy tensas entre los diversos actores sociales, sobre todo cuando se intentó forzar a los reinos americanos a realizar mayores aportes pecuniarios a la península. Los «beneméritos» nunca cejaron en sus intentos de obtener los puestos que los propios virreyes repartían entre sus criados. La Iglesia, por su parte, se mantuvo firme en defender los privilegios concedidos desde el siglo XVI, que la favorecían con la percepción de diezmos, inmunidad, cesión de tierras y beneficios fiscales. La administración fue ineficiente y progresivamente ciertas funciones del Estado fueron delegándose en manos privadas, particularmente en el Consulado. ${ }^{4}$ Finalmente, los comerciantes de Lima formaron grandes consorcios en el interior del virreinato que les permitieron lanzar una ofensiva contundente en el comercio atlántico a través de sus factores —los «peruleros»-, que dejó en malas condiciones tanto al comercio peninsular como al mismo sistema de galeones. ${ }^{5}$

En este contexto, y como expresión de la práctica política de la época, aparecieron diversos escritos sobre el Perú que trataron de diagnosticar y remediar alguno de estos males aunque, como afirma Amadori, la historiografía americanista no les ha prestado mucha atención. ${ }^{6}$. El fenómeno que más ha sido estudiado es la aparición de arbitrios en las décadas de 1620 y 1630, incentivada por el conde-duque de Olivares, la mayoría de los cuales tenía como finalidad hacer más eficiente la extorsión fiscal de las Indias.7 Un buen ejemplo es el «Parecer» del contador Hernando de Valencia, cuyo arbitrio explicaba los daños que había ocasionado la plantación de viñas en el Perú y recomendaba volver a prohibir el comercio de vinos peruanos para aumentar el consumo de aquellos procedentes de España. ${ }^{8}$ El arbitrio de Diego Pérez Gallego estaba orientado, por el contrario, a exaltar las virtudes del gobierno del virrey conde de Chinchón, pero también incluía un diagnóstico de los principales problemas del Perú y los remedios necesarios para subsanar los errores. ${ }^{9}$

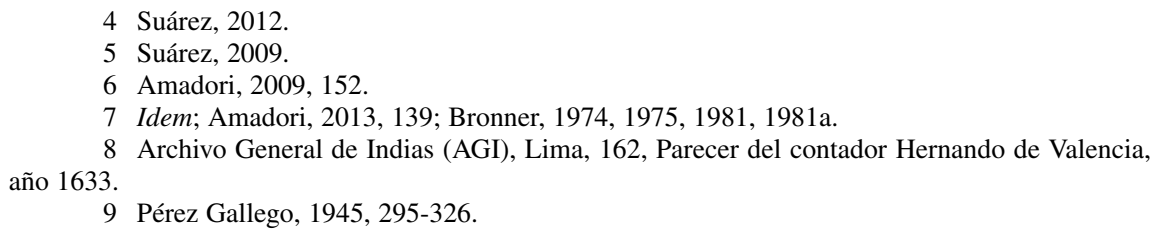


Pero la costumbre de elaborar arbitrios se inició en el siglo XVI. Como era usual, el arbitrista presentaba su papel ante la audiencia o el virrey, los que debían, a su vez, elevarlo al Consejo de Indias, que lo evaluaba para su posible presentación al valido o al rey. Otras veces el arbitrista enviaba directamente su escrito al consejo para esquivar la interferencia del virrey..$^{10}$ A cambio, el arbitrista esperaba reconocimiento y remuneración y, de esta manera, el arbitrio se convertía en un medio excepcional para la aplicación de medidas políticas y en una vía para el ofrecimiento de privilegios por parte del monarca.

Tal es el caso, por ejemplo, de Martín de Ocampo, que ilustra bien de qué manera el arbitrio operaba como un mecanismo de reforzamiento del honor y de reconocimiento pecuniario por las labores cumplidas en favor de la monarquía, que eran componentes esenciales del ejercicio político en el imperio de los Habsburgo. Ocampo llegó a América hacia mediados del siglo XVI y ganó, por la conquista de los indios de Popayán, dos encomiendas que posteriormente pasaron a manos del rey. En 1606 fue nombrado corregidor de Cuenca y se le encargó que «hiciese la jornada» de los indios jíbaros, lo cual no pudo hacer por oposición del virrey marqués de Montesclaros. Tomada su residencia, fue beneficiado con una renta de 400 ducados procedentes de indios vacos para «ayudar a poner en estado de religión tres hijas doncellas» y se afincó en Lima, en donde le entregó al virrey un arbitrio para el aumento de la producción de azogue en Huancavelica. ${ }^{11}$ En dicho arbitrio, Martín Ocampo explicaba cómo se perdían anualmente entre cinco y seis mil quintales de mercurio y proponía una fórmula para subsanar el problema. Luego de negociar con el virrey, se le hizo una merced por diez años, que consistía en que todo aquel que quisiese usar su técnica debía pedirle licencia, y Ocampo, además, recibiría la tercera parte de todo el azogue que se hubiese obtenido gracias al empleo de las sugerencias de su arbitrio.

No obstante la merced recibida, las relaciones con el virrey no fueron cordiales. Ocampo se quejaba lastimosamente de que había financiado con

10 Véase, por ejemplo, el caso del ingeniero y arbitrista lusitano Enrique Garcés, que descubrió el mercurio en el Perú, en Lohmann Villena, 1948; Biblioteca Nacional de Madrid, Mss. J 57, 3.041, «Copia de las dos cartas que Henrique Garcés scrivio desde Lima al virrey sobre minas y azogues y por no lo remediar él, las embió al Consejo el año de 1574», 26-29.

11 AGI, Lima, 143, Carta de Martín de Ocampo a SM, Los Reyes, 12 de mayo de 1613. Incluye el arbitrio de Ocampo, «Memorial de algunas advertencias muy del servicio de SM favorables al arbitrio y beneficio de los metales de azogue de Guancavelica que dio el capitán Martín de Ocampo al excelentísimo Marqués de Montesclaros, virrey destos reynos», 1613. 
su propia hacienda un segundo viaje a Huancavelica de seis meses para probar su técnica en hornos grandes y que, a pesar de que había logrado un aumento de diez mil quintales en la producción de azogue, el corregidor Pedro Osores de Ulloa, en alianza con el virrey, le había quitado los réditos del arbitrio para «sus fines particulares y grandes intereses». Y, agregaba Ocampo, de manera poco clara, «no me atrevo a declarar el fin y intento dellos», pues ya había adquirido la inteligencia para entender cómo se hacían las cosas en contra del servicio del monarca. ${ }^{12}$

Si el caso de Ocampo ilustra bien de qué manera los arbitrios operaban como un mecanismo de obtención de mercedes y reflejaba los pesos y contrapesos del poder político en el Perú, otros escritos, como el de Joan de Belveder, tienen el valor de ser, más bien, un testimonio de las prácticas económicas peruanas y del modo en que se burlaba la pretensión monárquica de controlar el territorio americano.

\section{Joan de Belveder, el comerciante}

El aragonés Joan de Belveder es conocido por haber publicado en Lima, en 1597, un libro de aritmética práctica ${ }^{13}$ y por haber elaborado a inicios del XVII un arbitrio que despertó gran interés en la corte. ${ }^{14}$ De Belveder solo se tenía noticia de que era natural de Tauste, en el reino de Aragón, y que había pasado a las Indias haciendo primero una escala en México para luego emprender viaje a Potosí, según se desprende de su libro de aritmética. Según Salavert, la primera referencia a Belveder se encuentra en la obra de Latasa, quien señalara que era «muy perito en las ciencia exactas» y que escribió su Libro general de las reduciones en los Reyes. A esta información Gómez Uriel agregó que era una «obra muy rara y curiosa». ${ }^{15}$ No se tiene certeza de la fecha de llegada de Belveder al Perú, pero la búsqueda en los notarios de Lima ha arrojado que ya desde 1584 se hallaba realizando distintas operaciones comerciales en territorio peruano.

12 Idem.

13 Belveder, 1597. Se puede consultar el manuscrito en: http://documentomovil.usal.es/ visor.php? $\mathrm{v}=$ dicter\&f=matematicas_bg_BelvederJoan ; consultado el 15 de diciembre de 2013 .

14 AGI, Lima, 143, «Memorial y apuntamiento sumario de algunos casos muy importantes al reparo de aumento de las rentas reales de su magestad para estos reynos del Perú y España que piden reformación, horden y concierto en su administración», Lima, 23 de agosto de 1612, sin foliar. Cf. Suárez, 2001, 43, 262; Suárez, 2001a.

15 Salavert, 1991; Gómez Uriel, 1884, 197. 
En efecto, la documentación notarial limeña indica que Belveder llegó al Perú a hacer fortuna mediante la actividad comercial. El registro más antiguo que se ha encontrado es un poder otorgado en 1584 por el regidor de Lima, don Luis Rodríguez de la Serna, quien le brindaba poder general para cobrar plata a sus deudores, entregar cartas de pago y realizar finiquitos. ${ }^{16}$ En 1589 se le encuentra recibiendo poder de Juan Sánchez, alguacil de corte, para que Belveder — quien se hallaba de partida a Tierra Firme - cobrase de Alonso Ramos más de 700 pesos que le había entregado para emplear mercaderías. ${ }^{17}$ Desde entonces el aragonés no aparece efectuando transacciones, probablemente por hallarse fuera de la capital, hasta 1592. En enero de este año Belveder concedió poder a su primo Cristóbal de Tudela, residente en Chile, para que cobrase a sus deudores, especialmente a Luis[?] de Agurto y Pedro de Ormachea, quienes le debían cierta cantidad de pesos. ${ }^{18}$ Casi todos los demás contratos de 1592 se refieren a transacciones que Belveder debía efectuar en la feria de Portobelo y en Panamá. Como se aprecia en el cuadro, y a pesar de que la información acopiada es solo una muestra, el matemático se dedicaba activamente al comercio atlántico e, incluso, en un contrato se le presenta como mercader de Lima. Como tal, realizaba las operaciones comerciales usuales de este período: recibía plata en barras y poderes para endeudarse en Tierra Firme, debía efectuar pagos de las compras que venían fiadas de años anteriores desde España y por todo ello, como factor, recibía una comisión. La documentación permite observar que Belveder gozaba de la confianza de sus corresponsales limeños. La viuda de Hernán Gonzáles, doña Juana de Cepeda, le encomendó seguir el curso de una transacción efectuada por su marido que involucraba 8.000 pesos ensayados y una obligación de 6.000 pesos por compra de mercaderías; confiando en sus habilidades comerciales, le dio poder para continuar con el negocio y traer el cargamento a Lima. ${ }^{19}$

16 Archivo General de la Nación del Perú (AGN), Sección Notarial (SN) Pedro Arias 11, Poder de Luis Rodríguez de la Serna a Joan de Belveder, Lima 1 de noviembre de 1584, 203r.

17 AGN, SN, Rodrigo Gómez de Baeza 48, Poder de Juan Sánchez Muchotrigo a Joan de Belveder, Lima, 7 de abril de 1589, 537r.

18 AGN, SN, Juan Gutiérrez 78, Poder de Joan de Belveder a Cristóbal de Tudela, Lima, 28 de enero de 1592, 390r.

19 AGN, SN, Rodrigo Alonso de Castillejo 19, Poder de Juana de Cepeda a Joan de Belveder, Lima, 4 de mayo de 1592, 136r y ss. 
REFORMA, ORDEN Y CONCIERTO EN EL PERÚ DEL SIGLO XVII

\section{PLATA RECIBIDA POR JOAN DE BELVEDER COMO FACTOR A TIERRA FIRME, $1592^{20}$}

\begin{tabular}{|c|c|c|c|}
\hline Emisor & Cargo & Cantidad & Empleo \\
\hline Gaspar Arias & Morador en Lima & $\begin{array}{l}5.000 \text { pesos } \\
\text { ensayados }\end{array}$ & $\begin{array}{l}\text { Comprar } \\
\text { mercaderías; recibir } \\
\text { ropa de Castilla; } \\
\text { obligarlo hasta por } \\
4.000 \text { pesos } \\
\text { ensayados }\end{array}$ \\
\hline Gaspar Arias & Morador en Lima & $\begin{array}{l}5.000 \text { pesos } \\
\text { ensayados }\end{array}$ & $\begin{array}{l}\text { Comprar } \\
\text { mercaderías a } \\
\text { Gaspar Hernández; } \\
\text { pagar } 1.000 \text { pesos a } \\
\text { Antonio Hernández } \\
\text { que trae ropa fiada } \\
\text { de España; pagar } \\
\text { fletes y derechos; } \\
\text { con lo sobrante } \\
\text { comprar } \\
\text { mercaderías }\end{array}$ \\
\hline $\begin{array}{l}\text { Constanza Díaz de } \\
\text { Santiago }\end{array}$ & $\begin{array}{l}\text { Viuda de Alonso } \\
\text { de Valencia, } \\
\text { escribano }\end{array}$ & $\begin{array}{l}2.000 \text { pesos } \\
\text { ensayados }\end{array}$ & $\begin{array}{l}\text { Comprar } \\
\text { mercaderías excepto } \\
\text { esclavos, vino o } \\
\text { jabón; los venderá } \\
\text { en Lima y recibirá } \\
\text { la sexta parte de las } \\
\text { ganancias. Además, } \\
\text { le da poder para que } \\
\text { la obligue en } 1.000 \\
\text { pesos }\end{array}$ \\
\hline Joan de Salvador & & $\begin{array}{l}4000 \text { reales de } \\
\text { plata castellana }\end{array}$ & $\begin{array}{l}\text { Comprar } \\
\text { mercaderías }\end{array}$ \\
\hline Cristóbal de Rivera & & $\begin{array}{l}11.000 \text { pesos } \\
\text { ensayados }\end{array}$ & $\begin{array}{l}\text { Comprar } \\
\text { mercaderías }\end{array}$ \\
\hline $\begin{array}{l}\text { Jerónimo López } \\
\text { Martel }\end{array}$ & & 1 barra de plata & $\begin{array}{l}\text { Para entregar a } \\
\text { Gaspar González } \\
\text { quien viene de } \\
\text { España; si no llega, } \\
\text { puede comprar } \\
\text { esclavos }\end{array}$ \\
\hline
\end{tabular}

20 Fuentes: AGN, SN, Diego Martínez 110, Recibo de Arias a Belveder, Lima, 29 de abril de 1592, 1007r y ss.; SN, Diego Martínez 110, Recibo de Arias a Belveder, Lima, 20 de abril de 1592, 1016r-1018r; SN, Rodrigo López de Castillejo 19, Recibo de Diaz de Santiago a Belveder, Lima, 30 de abril de 1592, 124v-125r; SN, Rodrigo López de Castillejo 19, Poder de Diaz de Santiago a Belveder, Lima, 30 de abril de 1592, 125r-127v; SN, Alonso Rodríguez 91, Recibo de Joan de Salvador a Belveder, Lima, 2 de mayo de 1592, 846r-848r; SN, Diego Martínez 110, Recibo de Cristóbal de Rivera a Belveder, Lima, 4 de mayo de 1592, 966r-968v; SN, Diego Martínez 110, Recibo de Pérez Martel a Belveder, Lima, 5 de mayo de 1592, 1107r y ss. 
Luego de la intensa actividad de 1592, Belveder reaparece en los registros notariales en los años 1596, 1597 y 1599. Al parecer, había estado en la provincia de los Pacajes realizando actividades vinculadas a la minería y a la obtención de tierras. En agosto de 1596 el aragonés, conjuntamente con Miguel de Alloza, familiar de la Inquisición, otorgaba un poder a Bartolomé de Palma, quien partía a Chuquiagua, para cobrar deudas en Pacajes y para representarlo ante las autoridades competentes en el reparto de minas de oro y plata, tierras e indios, así como para ejercer la administración de todo aquello que se le concediese. ${ }^{21}$ Como era usual, no todos los negocios llegaban a buen puerto. El 7 de enero de 1596 le daba un poder a Juan López, procurador de la real Audiencia, para que lo representase en todos sus pleitos, facultad que volvió a conceder nuevamente en julio del mismo año, esta vez a Pedro Ortiz de Valdelomar, quien ostentaba el mismo cargo. ${ }^{22}$ Gracias a un poder otorgado por Cristóbal de Rivera a los herederos del capitán Esteban de Trejos, se sabe que el primero seguía una causa contra Belveder, cuyos autos no se han hallado, pero probablemente estén vinculados al empleo de dinero en Tierra Firme (ver cuadro). En abril de 1599, las escrituras revelan que Belveder estaba partiendo a España, tal vez para comprar productos en Sevilla, y que luego retornó, pues entre 1604 y 1606 le estaba entregando al virrey conde de Monterrey su «Memorial»sobre el Perú. Finalmente, en la década de 1610 el matemático entabló dos causas, que muestran que ofrecía sus servicios para la elaboración de cuentas. El primer contencioso fue contra el canónigo don Andrés Díaz Abrego, por no haberle pagado sus servicios en las cuentas que llevaba con el padre Francisco Ortiz de Porras, residente en Quito, y por las del albaceazgo del padre Joan Díaz de Abrego, quien tenía doctrina en el pueblo de Illima, en Trujillo. El segundo pleito fue contra el mayordomo de la cofradía de San Nicolás, en 1614, quien, igualmente, no cumplió con el pago de su trabajo. ${ }^{23}$

21 AGN, SN, Diego Jiménez 102, Poder de Miguel de Alloza y Joan de Belveder a Bartolomé de Palma, Lima, 15 de agosto de 1596, 274r.

22 AGN, SN, Cristóbal de Aguilar Mendieta 3, Poder de Belveder a Juan López, Lima, 7 de enero de 1596, 35v-37r; SN, Cristóbal de Aguilar Mendieta 4, Poder de Belveder a Pedro Ortiz de Valdelomar, Lima, 11 de julio de 1596, 682r.

23 Archivo Arzobispal de Lima, Causas Civiles, IX, 32; Cofradías, LXXII, 5. 


\section{Joan de Belveder, el matemático}

Fruto de la experiencia adquirida en el comercio peruano, Belveder emprendió la aventura de escribir un manual de aritmética práctica con el fin de facilitar las cuentas que llevaban los mercaderes y los funcionarios. El Libro general del reduciones de Belveder es, junto con el de Juan Díez Freyle,$^{24}$ un exponente de la presencia de matemáticos en América en el siglo XVI, que intentaron arrojar un poco de claridad al caos monetario que imperaba en el Perú.

En efecto, la producción y circulación de oro y plata en el Perú estuvo acompañada de una desordenada política monetaria. A pesar de que el metal peruano estaba presente en territorio europeo y era un medio de pago esencial en toda América y Filipinas, el circulante, antes de 1568, estaba compuesto por pedazos de oro y plata, tejos y barretones que se denominaban «plata corriente», y que eran valorados en pesos y tomines. ${ }^{25} \mathrm{El}$ disco acuñado recién apareció con la creación de las casas de moneda de Lima y Potosí. La primera funcionó de manera continua tan solo de 1568 a 1588, de manera que fue la casa de moneda de Potosí la que cumplió con el abastecimiento de circulante amonedado la mayor parte de los siglos XVI y XVII. ${ }^{26}$ En la casa de Potosí se acuñaban discos de metal (los famosos «patacones peruleros») y se quintaba la plata en barras, siendo esta última la especie por excelencia usada en el comercio de exportación.

Pero las casas de moneda no resolvían el enjambre compuesto por el uso de diversas unidades monetarias. Las estrictamente peruanas eran todas, menos una, unidades de cuenta: el peso de 12 reales y medio (del «rey»o de «tributos»), el peso ensayado de 13 reales y un cuartillo (peso ensayado de «mercaderes») y el peso de 9 reales (conocido como peso corriente). $\mathrm{La}$ única moneda que existía como disco de plata era el peso de 8 reales («patacón») y sus fracciones, cuya reducida acuñación causó problemas de liquidez en los pagos menores. No obstante ser estas las unidades peruanas, en los libros de cuentas se usaban unidades monetarias de otras partes del imperio, como los pesos de buen oro, ducados, coronas, etc. y, finalmente, también se empleaba como medio de pago la plata «labrada» o piñas de plata, que no habían pagado el quinto al rey y cuyo precio se calculaba por el peso en marcos valorado en pesos ensayados.

\footnotetext{
24 Díez Freyle, 1556.

25 Moreyra Paz Soldán, 1994, 126 y ss.; Lazo García, 1992, I, 180-182.

26 Suárez, 2001, 41 y ss.
} 
Los libros fiscales y los mercaderes empleaban en sus cuentas pesos ensayados - con los que valoraban las barras de plata-, pesos de a 8 y pesos de oro de distintos quilates. Para la conversión de pesos ensayados a pesos de a 8 se usaban los pesos de a 9 reales, que era una unidad de cuenta que resolvía los problemas matemáticos de convertir directamente los pesos ensayados en pesos de a 8 , y viceversa, puesto que solo se usaban quebrados, no decimales. A la dificultad matemática habría que añadir las fluctuaciones del mercado monetario y los intereses, que modificaban las tasas de cambio. De modo de que no había una sola tasa de cambio para la conversión de monedas. El uso de los pesos de a 9 simplificó enormemente este impasse, pues al permitir que se usaran fórmulas sencillas - como reducciones al $143 \%, 144 \%$, etc.- las operaciones de cambio se facilitaron: una conversión de pesos ensayados al $144 \%$ significaba que 100 pesos ensayados valían 144 pesos de a 9 reales, y de allí convertirlos a patacones era tarea muy simple. ${ }^{27}$

Este caos motivó a Joan de Belveder a escribir su Libro general de reduciones, que ha merecido un detenido estudio por parte de Salavert Fabiani y cuyo ejemplar, existente en la Biblioteca Nacional de Madrid, ha sido digitalizado y transcrito en la Universidad de Salamanca. ${ }^{28}$ En el libro, Belveder explica que en el Perú circulaba una gran cantidad de metales y que la gente estaba involucrada en este trato según su caudal. No obstante, la mayoría era gente inexperta: son «poco praticos y aspertos en la cuenta que les es necesario saber de las reduciones de unas monedas a otras, y del valor de cada una dellas, porque suben y baxan sus intereses a más y a menos precio en muchos tiempos del año».29 Por esta razón, continúa Belveder, con frecuencia se producían fraudes y engaños por los errores que se cometían en las cuentas. Así, para ahorrar el trabajo de hacer las conversiones, el autor había elaborado el libro, que contenía tablas de conversión del valor de barras y tejos de oro según su peso desde 1.000 hasta 2.400 maravedís el marco; tablas de conversiones de pesos ensayados a corrientes (y viceversa) con intereses desde el 8 hasta el $50 \%$; tablas de conversión de pesos ensayados a buen oro y viceversa; de pesos ensayados

27 Ibidem, 42-43.

28 Salavert, 1991; consultar en Biblioteca General Histórica de la Universidad de Salamanca la versión digital del original de la Biblioteca Nacional de Madrid y transcripción, http://bibliotecahistorica.usal.es . Existen otros ejemplares en la Biblioteca Nacional del Perú, la John Carter Brown Library y la Biblioteca Nacional de Maestros de Argentina, cuya versión digital se puede revisar en: http://www.bnm.me.gov.ar.

29 Belveder, 1597, Vr. 
a ducados, y de ducados a pesos ensayados, «y de muchas monedas y reduciones de unas a otras, y de otra a otras, desde menor a mayor cantidad, en qualquier especie dellas». ${ }^{30}$ De esta manera se evitarían los errores que ocurrían en épocas de flotas para Tierra Firme y México, o en cualquier ocasión que se requiriese hacer una conversión.

Como explica Salavert, el libro de Belveder podría dividirse en tres partes. La primera dedicada al ensayo de los metales y a los pesos y finezas del oro y la plata; la segunda, sin duda la más extensa, que contiene tablas de conversión y cálculos sobre los derechos que pagaban mercaderías y metales; y la tercera, que ofrece las reglas aritméticas empleadas en el diseño de las tablas y 42 problemas referidos a la regla de tres y al de la falsa posición. ${ }^{31}$ Ya en la introducción del libro, la «Declaración del dineral de plata de los ensayadores, y cómo usan de su valor en sus ensayes», se puede observar que el matemático aragonés estaba «inmerso en el ambiente del arbitrismo hispano», ${ }^{32}$ pues insiste en que los quintos y demás derechos reales debían cobrarse en la misma «especie de cada pieza» con el fin de que el monarca se beneficiase de la misma manera que se favorecían los que quintaban los metales. ${ }^{33} \mathrm{Al}$ final del texto, Belveder hace una reivindicación de su obra con el fin de que no se le considere ignorante de las matemáticas que se enseñaban en la universidades, y sugiere a los aficionados la lectura de las «Matemáticas de Moya del Arte Mayor y Menor, como las de Tartalla, el alemán, Euclides, Oroncio, Burgos y Ortega, y las de otros muchos autores excelentes, antiguos y modernos». ${ }^{34}$ Estas menciones sugieren el conocimiento de figuras importantes de las matemáticas del Renacimiento, como el clásico Euclides, los italianos Tartaglia y fra Luca di Burgo, el francés Oronce Finé, y tres figuras ilustres de las matemáticas españolas del siglo XVI: Juan Pérez de Moya, Marc Aurel —alemán, autor del primer libro de álgebra impreso en España-y Juan de Ortega. ${ }^{35}$

La obra de Joan de Belveder es pionera, junto con la de Díez Freyle, de una tradición que comenzó en el siglo XVI consistente en imprimir en Lima manuales con tablas de conversión para facilitar las cuentas de los mercaderes, de los oficiales reales y de la población en general. En el siglo

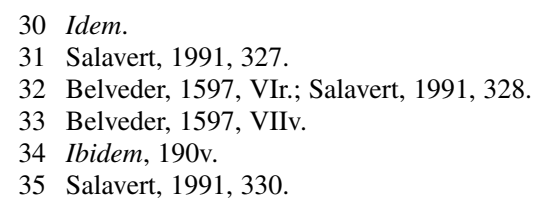


XVII aparecerían más obras, como el Libro de plata reducida de Francisco Juan de Garreguilla (1607), las Tablas para la reducción de las barras de plata de todas leyes de Pedro de Saldías (1637), o la Arismética peruana de Diego de Morillas (1693), que marcarían un hito en la historia de las matemáticas prácticas del Perú virreinal.

\section{El arbitrio}

Las habilidades de Belveder no se limitaron a develar los misterios del caos monetario peruano. Fruto de las tres décadas —o más- de permanencia en el Perú, el aragonés entendió hasta qué punto la administración del reino era precaria y detectó los puntos más vulnerables de la capacidad del estado virreinal de extraer de manera eficiente los frutos del territorio peruano. A inicios del siglo XVII entregó al virrey conde de Monterrey (1604-1606) su extenso «Memorial y apuntamiento» compuesto de 38 puntos, con el fin de llamar la atención del monarca acerca de los grandes fraudes que se cometían contra la real hacienda y de las medidas que él consideraba que se debían tomar para ordenar la imposición fiscal. Habiendo muerto el virrey Monterrey, en 1607 Belveder envió una copia al Consejo de Indias y al monarca, y en 1609 le pidió al nuevo virrey marqués de Montesclaros su parecer acerca del escrito. Este no contaba con copia del arbitrio y se limitó a decir que eran muchos los puntos y que trataba de temas generales sobre los que todos hablaban en las Indias, así que reservaba su opinión hasta leer el memorial. Montesclaros se lo pidió a Belveder, y la copia que se ha revisado está fechada en Lima, el 23 de agosto de 1612 , que fue la que se envió nuevamente al Consejo de Indias. ${ }^{36}$

El arbitrio se inicia con una emotiva justificación de las razones por las cuales Belveder escribía el memorial. Su móvil era la observación de la debilidad de los reinos de España y la «flaqueça, desconsuelo y pobreça de sus vasallos» ocasionadas por el descuido con el que se estaban administrando sus reinos. España había sido «señora de las gentes» y ahora se hallaba sola, descuidada, y expuesta a la desventura y a la posible ruina de la monarquía. Las «extranjeras naciones enemigas de España» la habían asfixiado con «asientos, logros, cambios intolerables y usuras». Obligada a defender la «universal iglesia», España había tenido que desplegar grandes

36 AGI, Lima, 35, Carta del virrey Montesclaros a SM, Callao, 11 de abril de 1608; AGI, Lima, 143, «Memorial» de Belveder; AGI Lima 570, 284v. 
ejércitos y armadas por Italia, Alemania, Francia, Flandes y el África, y socorrer los «nuevos mundos orientales y occidentales». Todo ello había consumido los grandes tesoros llegados de las Indias y también había reducido sus antiguas rentas y patrimonio, de modo que los reinos de España se hallaban «afligidos» y al borde del abismo. Ya que la verdadera arma ofensiva y defensiva que sustentaba los reinos era el dinero, Belveder, como «ministro çeloso y leal vasallo» se hallaba conmovido por la extrema necesidad del tesoro real y por ello sugería tomar ciertas medidas para poner orden con el fin de aumentar las rentas del monarca. ${ }^{37}$

Los 38 puntos tratados en el arbitrio se pueden agrupar en ocho temas generales: cómo controlar la fundición y la acuñación de plata aumentando el pago de los quintos reales; cómo evitar el contrabando del azogue; qué hacer con las deudas de las cajas reales; cómo fiscalizar los gastos del estado; qué nuevos impuestos se debían imponer; qué hacer con el reparto de tierras; cómo controlar el comercio. Finalmente, el arbitrista hace un análisis global de la situación del reino del Perú y del modo de corregir los problemas.

Con respecto al primer tema, Belveder instaba a poner orden en Potosí y en las demás minas del Perú donde hubiesen fundidores y ensayadores, pues la cantidad de metales que circulaba sin quintar era elevada y mucha terminaba en manos de la Iglesia o de los plateros. Así, el monarca debía valerse de sus legítimas rentas y poner un plazo para que todo los metales y joyas pagasen quinto, frenando el «atroz atrevimiento» de los oficiales reales que habían consentido que los quintos se negociasen..$^{38}$ Igualmente, se debía obligar a los ensayadores a llevar libros encuadernados, en donde señalasen «por letra y no por cifra de quenta de güarismo ni castellana», todos los metales que hubiesen entrado en su poder para quintar, y que estos libros se enviasen a la Casa de Contratación de Sevilla. Todo esto ya que por descuido o por codicia no se consignaban por escrito las cuentas. Incluso, los funcionarios habían sacado oro y plata de las cajas reales, procedentes de los quintos, para pagar sus deudas y «granjerías» y, adicionalmente, se habían falseado los ensayes — como sucedió en Popayán—, con lo cual se habían cometido grandes daños y fraudes contra la hacienda real. Sobre este punto, dice Belveder, entregó al virrey marqués de Montesclaros un escrito en 1608, que permitiría que cesasen los fraudes. Finalmente, pro-

37 AGI, Lima, 143, «Memorial» de Belveder.

38 Ibidem, puntos 1,2 y 3. 
ponía que toda la plata en pasta que llegase de las Indias occidentales y orientales - y del Congo y Angola - se acuñase en Sevilla, y recién después se entregase a sus dueños, para evitar así la fuga de metales. ${ }^{39}$

La circulación del azogue de Huancavelica también tenía que reorganizarse. Ni los mineros asentistas ni sus mayordomos debían sacar azogue de los almacenes reales para pagar salarios, deudas, herramientas, vestidos o calzados. Según Belveder, el azogue se vendía «descaminadamente» para pagar los costos de operación de las minas y también para pagar a los indios que trabajaban en ellas, a pesar de que, en teoría, la caja de Lima cubría el pago de los salarios. El problema era, según el aragonés, que la tercera parte de los indios que se les repartía a los mineros eran ocupados como «guardas de sus ganados mayores y menores y traxines de sus granjerías y alquilan a diversas personas por la cudiçia de los xornales que les pagan doblado del que ellos les pagan» y, aún así, cobraban de la caja real sus jornales. Fruto de este efugio, los mineros debían a la caja más de 600.000 pesos — sin contar los réditos, que ascenderían a 30.000 - con notable menoscabo de los reales ingresos. Sobre este punto también había entregado al virrey Montesclaros otro escrito de 22 capítulos en $1608 .{ }^{40}$

El mal manejo de las cajas reales es otro de los temas examinados en el memorial. La mayoría de las cajas del Perú había acumulado deudas atrasadas y recurrido a préstamos, incluyendo la caja de Potosí. ${ }^{41}$ Pero no se sabía con exactitud quiénes eran los deudores, pues no se registraban las obligaciones en libros. Belveder proponía que se ordenase a los oficiales reales llevar cuenta escrita con «abecedario» de todas las deudas rezagadas de las cajas, con el fin de poder ubicar a los deudores. En el Perú, igual que en España, se había perdido una gran cantidad de tesoro por haberse fugado los deudores y las personas que tenían a su cargo la administración de las cajas, algunos de ellos «disfraçandose en los trages, mudándose los nombres como lo an echo corregidores, administradores, receptores de cobranças reales... mercaderes, frayles y clérigos dislocadamente», y ello por estar confiados en que nadie los iba a castigar. Proponía perseguir a los deudores y castigar a aquellos — como los dueños de navíos- que los ayudasen a escapar, y sugería cobrar intereses, a razón de 20.000 el millar, del dinero adeudado a la real hacienda. ${ }^{42}$ Para estos clérigos y funcionarios

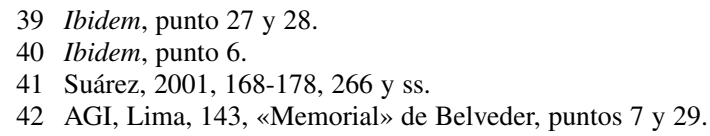


«fugitivos», muchos de los cuales habían amasado fortunas en corregimientos, doctrinas, rentas de españoles e indios y, en general, en la administración del estado, el aragonés proponía que entregaran fianzas y que no pudiesen salir del Perú sin una constancia de las actividades en las que habían estado involucrados. ${ }^{43}$ Del mismo modo, y con el fin de hacer más eficiente el control de las cajas, había que fiscalizar minuciosamente los gastos militares y la construcción de navíos en el Callao y Guayaquil, puesto que no se rendían cuentas de lo que se compraba ni de los salarios que se pagaban..$^{44}$ Belveder consideraba, además, que se podrían imponer nuevos impuestos - como gravar con quintos a la producción de estaño, cobre y plomo-, crear un estanco del jabón español prohibiendo que se fabricara en el Perú, monopolizar la venta de los tributos de indios entregados en especie, instalar aduanas y puertos secos, y volver a medir, «redimir y componer» las tierras y pastos del Perú, Tucumán, Chile, Paraguay y Brasil para obtener nuevas rentas reales. Por último, el arbitrista afirmaba que había crecido tanto el comercio de libros en el Perú que deberían pagar derechos, incluso los adquiridos por colegios y universidades, y que las órdenes religiosas debían pagar impuestos sobre el vino, el aceite y la cera que consumían. ${ }^{45}$

El tema del fraude y el contrabando en el comercio es, junto al de la administración fiscal, uno de los temas centrales del arbitrio. Advirtiendo, gracias a su propia experiencia como comerciante, las múltiples estrategias empleadas por los mercaderes para eludir el régimen impositivo, Belveder planteaba establecer férreas medidas de control que acercan su memorial a lo que sería un proyecto disparatado. Por ejemplo, sugería que se ordenara que los secretarios de los tribunales y los escribanos públicos entregaran a la contaduría mayor una relación sumaria — jurada y firmada — de todos los pleitos pendientes o acabados de los últimos 30 años relacionados con el fisco y el empleo de mercaderías en España, Tierra Firme, México y China; dicha relación contendría el monto de las condenas y los nombres de los fiadores de los comerciantes. De esta manera, aseguraba Belveder, se podría conocer los grandes fraudes que se cometían en el pago de almojarifazgos por los encomenderos — factores- del Perú. ${ }^{46}$ Además, señalaba que sería muy útil que todos los escribanos entregaran una relación de

43 Ibidem, punto 11 .

44 Ibidem, punto 20.

45 Ibidem, puntos 18, 19, 21, 30, 31, 35 у 36

46 Ibidem, punto 8. 
todos los recibos de plata - es decir, contratos a través de los cuales se entregaba dinero para comprar mercaderías - realizados en los últimos 30 años para comprar en Guayaquil, Panamá, Nicaragua, Nueva España, China y Castilla, con lo cual se conseguiría establecer el monto por el que se defraudaba a la real hacienda en el pago de la avería. Belveder consideraba que el costo de la armada del Mar del Sur no era compensado con el pago efectivo de este impuesto, que debía ser considerablemente más alto debido a la gran actividad comercial en el Pacífico. ${ }^{47}$ Asimismo, proponía una medida extrema: que todos los escribanos y secretarios de tribunales de Tierra Firme entregaran a la contaduría mayor una relación de todos los metales que hubiesen ido registrados o «por registrar» en todos los navíos que hubiesen zarpado en las últimas tres décadas con destino a Castilla, Cartagena y «otras partes». También planteaba que los oficiales reales hicieran una relación sumaria de todas las partidas de mercaderías que llegaron de Castilla para pasarse al Perú, de quiénes las llevaron y de cuánto pagaron de almojarifazgos. Con estas medidas, aclaraba Belveder, se podría saber con exactitud a cuánto ascendía el fraude a la real hacienda en la carrera de Indias y se frenarían los «atrevimientos y descuidos tan grandes» de funcionarios y mercaderes. ${ }^{48}$

Ciertamente, aseguraba el arbitrista, «es usança muy antigua y guardada entre todos los mercaderes del orbe el procurar con toda ynstançia la usurpación de derechos [...] y parece que más depravadamente se continua la dicha usurpación» en el comercio con las Indias. Por esta razón, tanto en Sevilla como en Lisboa se deberían sellar los fardos de mercaderías con la «ere u otro material yncorrutible» y confiscar todos aquellos que no estuviesen marcados. Ya que una de las principales quejas de los comerciantes era la apertura de sus fardos, los sellados no tendrían que abrirse, sino tan solo llevar un registro para presentarlo al corregidor o a los oficiales reales. ${ }^{49} \mathrm{Y}$ para frenar el ingenio de los «tramposos y codiciosos» que tenían haciendas mal habidas y procuraban encubrir sus negocios, se debía prohibir que se pudiesen enviar mercaderías o metales en nombre de terceras personas, aunque fuesen eclesiásticos. ${ }^{50}$ Así, cuando llegasen al puerto de Perico, en Panamá, tendrían que ingresar los cargamentos en la casa de Contratación para que luego se entregaran a las personas que efectivamen-

\footnotetext{
47 Ibidem, punto 9.

48 Ibidem, punto 10.

49 Ibidem, punto 24

50 Ibidem, punto 25.
} 
te eran dueñas de la plata o mercaderías. Con ello, además, se evitaría la evasión del registro de plata, «por quanto consta por evidencia muy clara [...] que en este reyno del Piru y Mar del Sur y como se hace en la mar del norte de Tierra Firme a Sevilla y de las Yndias Brasil y Guinea a Lisboa el no registrarse la tercera parte del tesoro [de] particulares $» .{ }^{51}$ Del mismo modo, se debería nombrar a un escribano de avaluaciones en el Callao para que elaborase un resumen de los últimos 40 años, puesto que los oficiales reales no tenían idea de cómo cobrar los impuestos. Sobre este tema había remitido al Consejo de Indias y entregado al virrey Montesclaros un escrito de 14 capítulos. ${ }^{52}$ Era, asimismo, medular que existiese un tribunal del Consulado en Lima, debido a que los jueces de la Audiencia de la ciudad no eran peritos en los asuntos mercantiles y dilataban absurdamente los pleitos. Por último, se deberían nombrar pilotos mayores y cosmógrafos, que hubieran rendido examen, para que navegaran acompañados de oficiales que respetasen las rutas de navegación, y como complemento había que cerrar el comercio por Buenos Aires, para evitar el goteo de metales y gente por esta vía..$^{53}$

El comercio con la China mereció varios puntos del «Memorial» de Belveder. El aragonés afirmaba que el comercio de sedas orientales había aumentado tanto por la falta de aplicación de sanciones contra el contrabando de ropa de la China, que se habían armado telares para ellas so pretexto de que procedían de México, y así paseaban «arreadas y costosas» por las calles, negras, mulatas e indias, y España se hallaba «perdida y estos reynos asolados». Solo se debería permitir, pues, que se tejieran sedas de Castilla o de México y se tendría que penar severamente a los infractores. Además, nuevamente sugería que los escribanos dieran información acerca del tesoro remitido a Guayaquil y México en los últimos 30 años, y de las mercaderías llegadas al Callao, que todo el tráfico por el Pacífico también pagara avería - aunque no usasen a la armada del Mar del Sur- y almojarifazgo, y que se detectase por este medio a los que estaban envueltos en el contrabando. ${ }^{54}$ Belveder calculaba que en las últimas tres décadas se habían remitido más de 60 millones de pesos para la compra de mercaderías chinas, y que el monarca había perdido unos 10 millones por concepto de impuestos no pagados. La única solución era, decía Belveder, cerrar

51 Ibidem, punto 26.

52 Ibidem, puntos 16 y 17.

53 Ibidem, puntos 23 y 33 .

54 Ibidem, puntos 4, 5, 12, 13 y 14 . 
completamente el comercio del galeón de Manila, y que el trato con Filipinas se realizara desde Castilla por el cabo de Buena Esperanza. ${ }^{55}$

El punto 37 lleva por título la «advertencia muy considerable» y en él Belveder hace un balance general de la situación económica del Perú y del por qué el monarca no estaba sacando los frutos que debería del territorio. Afirma el aragonés que la población del Perú había crecido diez veces en los últimos 30 años por la llegada de españoles y esclavos y que, sin embargo, las flotas que arribaban de España no habían aumentado de acuerdo al incremento de habitantes. La causa principal era, sin duda, la autosuficiencia del Perú. Se habían plantado viñas, olivares, azúcar, y se fabricaban tejidos y sombreros en los obrajes. También se producía jabón, jarcias, cultivos de panllevar, brea, metales, loza, cordobanes, azufre, salitre y se «benefician, labran y fabrican con primor, arte y puliçía» una gran variedad de objetos y mercancías. Solo faltaba, dice Belveder, que en el Perú se sembrara azafrán y se fabricara papel para que no tuvieran ninguna necesidad de España, puesto que las telas de calidad procedían de la China. Así, la producción peruana y el comercio asiático habían «enajenado» a España más de 130 millones de pesos, que serían difíciles de «restaurar». Los cargadores de España debían estibar los navíos con arena y piedras porque los contratos entre el Perú y España estaban «perdidos y asolados». Belveder ofrecía una solución a este problema en cuatro puntos: cesar el cultivo de viñas, olivares y cañaverales, y que los productores pagasen un diezmo destinado a la defensa de España en Europa; prohibir la creación de nuevos obrajes, que los ya existentes solo produjesen ropa ordinaria y que, igualmente, pagasen un diezmo de composición sobre la producción; que las fábricas de jabón, jarcias y brea fueran arrendadas por el monarca y se creara un estanco para estos productos; y que, finalmente, las fundiciones de cobre, estaño, pasamanos de seda y oro y plata, cueros, vidrio, lozas, etc. fuesen manejadas por oficiales reales y se hiciese un padrón general de todos los productores del Perú..$^{56}$

$\mathrm{El}$ «Memorial» de 1612 agregaba un punto más, relativo a los «fraudes y colusiones encubiertas» en los gastos públicos, sobre todo en los pagos y compras de la Armada en Lima y en todos los puestos militares que existían en el reino. Según Belveder, las cuentas estaban disfrazadas y ninguna compra estaba debidamente justificada, pues se usaban «recaudos

55 Ibidem, punto 15 .

56 Ibidem, punto 37. 
simples». Los contadores y comisarios cometían robos y fraudes, eran sobornados y, por último, estaban involucrados en «cambios, asientos, recambios, logros y usuras». El aragonés terminaba su arbitrio afirmando que todos los vasallos fieles al rey se lamentaban, «con lágrimas de los corazones», de la codicia, el descuido, la ignorancia y la mala administración del Perú, y pedía a Dios que la gran monarquía no pereciera en manos de los enemigos de la santa Iglesia. ${ }^{57}$

\section{Consideraciones finales}

Probablemente el diagnóstico final de Belveder pueda resultar evidente. Muchos de sus coetáneos escribieron acerca del peligro que se estaba corriendo al dejar que el Perú desarrollara una economía que prescindiera de los productos españoles. Incluso, en 1590 el propio virrey marqués de Cañete advirtió al monarca casi lo mismo que Belveder: que el Perú estaba habitado por españoles que no habían nacido en la Península, que era autosuficiente en alimentos y textiles, que el tráfico con China lo abastecía de textiles de calidad, y que todo esto podía ser la ruina del comercio y del dominio de España sobre América. ${ }^{58}$ Funcionarios y comerciantes peninsulares insistieron en que era necesario mantener al reino «necesitado», puesto que esta sería la única garantía para conservar el vínculo entre España y las Indias. No obstante, el arbitrio de Belveder goza de la virtud de haber sido realizado por una persona que entendía muy bien cómo funcionaba el comercio, cómo se administraba la real hacienda y comprendía, lo cual era difícil, los hilos del caos monetario del Perú. Belveder fue un prolífico arbitrista, como lo demuestran las repetidas referencias en su «Memorial» a papeles entregados al virrey o enviados al Consejo de Indias, de los cuales no se cuenta con información adicional. No todas sus férreas medidas correctivas se aplicaron, por lo menos las más dramáticas. La información que exigía recolectar Belveder hubiese sido una bendición para el historiador contemporáneo, pero habría generado un gran descontento entre comerciantes y funcionarios de la época. Pero, al parecer, algunas de sus propuestas sí se escucharon aunque, por supuesto, no se puede afirmar que la adopción de las medidas contenidas en sus escritos fuese causa directa

57 Ibidem, punto 38.

58 Borah, 1954, 124. 
de la lectura del «Memorial» sino, más bien, del efecto de una corriente de opinión en la cual se enmarcaba el arbitrio. Casi inmediatamente, en 1613, se fundó un Consulado para mercaderes, en 1617 se visitó la caja de Potosí y en 1625 se realizó una visita general del Perú, que demostró que varios de los problemas detectados por Belveder eran acertados, como la malversación en las cajas reales y el endeudamiento absurdo de estas. Lo cual, claro está, no significa que la situación de la real hacienda mejorara sensiblemente en el siglo XVII. Muchos de los problemas observados por Joan de Belveder perdurarían, incluso empeorarían, durante el tiempo de gobierno de los Habsburgo y algunas de las esperadas medidas correctivas solo llegarían con el ascenso de la nueva dinastía borbónica.

Recibido el 16 de enero de 2014 Aceptado el 6 de abril de 2014

\section{Bibliografía}

Amadori, Arrigo: «Que se dé diferente modo al gobierno de las Indias, que se van perdiendo muy a prisa. Arbitrismo y administración a principios del siglo XVII», Anuario de Estudios Americanos, 66-2, Sevilla, 2009, 147-179.

Amadori, Arrigo: Negociando la obediencia. Gestión y reforma de los virreinatos americanos en tiempos del conde-duque de Olivares, Madrid, CSICUniversidad de Sevilla - Diputación de Sevilla, 2013.

Belveder, Joan de: Libro general de las reduciones de plata y oro de diferentes leyes y pesos, de menor a mayor cantidad, y de sus intereses a tanto por ciento, con otras reglas y avisos muy necesarios para estos reynos del Pirú. Compuesto por Joán de Belveder, natural de la villa de Tahuste, en el reyno de Aragón. Dirigido al Doctor Joán Ruiz de Prado, Inquisidor Apostólico de estos reynos del Pirú, etcétera, Lima, Antonio Ricardo, 1597.

Borah, Woodrow: Early Colonial Trade and Navigation between Mexico and Peru, Berkeley, 1954.

Bronner, Fred: «Peruvian Arbitristas under Viceroy Chinchon, 1629-1639», Scripta Hierosolymitana, Jerusalén, 1974, 34-78.

Bronner, Fred: «Un agente extraordinario de Olivares para el Perú: el contador Hernando de Valencia», Boletín del Instituto Riva-Agüero, 10, Lima, 1975, 29-62.

Bronner, Fred: «Advertencia privada de un virrey peruano del siglo XVII a su presunto sucesor», Revista de Indias, XLI-163-164, Madrid, 1981, 55-77.

Bronner, Fred: «Tramitación legislativa bajo Olivares. La redacción de los arbitrios de 1631», Revista de Indias, XLI-165-166, Madrid, 1981a, 411-443. 
Díez Freyle, Juan: Sumario compendioso de las quentas de plata y oro que en los reynos del Piru son necesarias a los mercaderes y todo genero de tratantes. Con algunas reglas tocantes al Arithmética, México, Juan Pablo Bressano, 1556.

Elliott, John: España y su mundo (1500-1700), Madrid, Taurus, 2007.

Gómez Uriel, Miguel: Bibliotecas antigua y nueva de escritores aragoneses de Latassa aumentadas y refundidas en forma de Diccionario BibliográficoBiográfico, I: A-G, Zaragoza, Imprenta de Calisto Ariño, 1884.

Lazo García, Carlos: Economía colonial y régimen monetario. Perú, siglos XVIXIX, Lima, Banco Central de Reserva, 1992.

Lohmann Villena, Guillermo: «Enrique Garcés, descubridor del mercurio en el Perú: poeta y arbitrista», Anuario de Estudios Americanos, 5, Sevilla, 1948, 439-482.

Lynch, John: «The Institutional Framework of Colonial Spanish America», Journal of Latin American Studies, 24, Quincentenary Supplement, Cambridge, 1992, 69-81.

Lynch, John: Los Austrias (1598-1700), Historia de España, XI, Barcelona, Crítica, 1993.

Moreyra Paz Soldán, Manuel: Estudios Históricos, I-IV, Lima, Instituto RivaAgüero, 1994-1995.

Múzquiz de Miguel, José Luis: El Conde de Chinchón, virrey del Perú, Madrid, CSIC, 1945.

Perdices de Blas, Luis y Reeder, John: Diccionario de Pensamiento Económico en España (1500-2000), Madrid, Fundación ICO - Editorial Síntesis, 2003.

Salavert Fabiani, Vicent: «Notas acerca del Libro General de las reducciones de plata y oro... (Lima, 1597) de Juan de Belveder», en Bujosa I Omar, Francesc; Miqueo, Consuelo; Fernández, Asunción y Martínez, Alvar (eds.): Actas del IX Congreso Nacional de Historia de la Medicina, Zaragoza, Prensas Universitarias y Ayuntamiento de Zaragoza, 1991, 321-333.

Pérez Gallego, Diego: «Alguna parte del acertado y prudente gobierno que tuvo en los reynos del Piru el Excmo. Señor conde de Chinchón, virrey desde el año de 1629 hasta el de 1640», en Múzquiz de Miguel, 1945, 295-326. Suárez Espinosa, Margarita: Desafíos transatlánticos. Mercaderes, banqueros y el estado en el Perú virreinal, 1600-1700, Lima, Instituto Riva-AgüeroPontificia Universidad Católica del Perú - Fondo de Cultura Económica, 2001.

Suárez Espinosa, Margarita: «Los límites del estado virreinal. Mercaderes, banqueros y real hacienda en el Perú, siglo XVII», en Millones, Luis y Villa Rodríguez, José (eds.), Perú: el legado de la Historia, Sevilla, Fundación El Monte, 2001a, 193-206.

Suárez Espinosa, Margarita: «El Perú en el mundo atlántico (1520-1739)», en Contreras, Carlos (ed.), Compendio de historia económica del Perú. 


\section{MARGARITA SUÁREZ}

Economía del período colonial temprano, 2, Lima, Banco Central de Reserva, 2009, 229-311.

Suárez Espinosa, Margarita: «Galeones, mercaderes y virreyes: tensiones en el imperio hispánico en la segunda mitad del siglo XVII», en Vila Vilar, Enriqueta y Lacueva, Jaime (coords.), Mirando las dos orillas: Intercambios económicos, sociales y culturales entre Andalucía y América, Sevilla, 2012, 165-182. 